\title{
PENENTUAN SIFAT-SIFAT FISIS PARTIKEL DARI BEBERAPA JENIS BEDAK BAYI DAN HUBUNGANNYA DENGAN PROSES INHALASI
}

\author{
Sri Handani ${ }^{1}$, Sri Mulyadi ${ }^{1}$, Ayuningtyas ${ }^{1}$ dan Eko Pudjadi ${ }^{2}$ \\ ${ }^{1}$ Jurusan Fisika, FMIPA Universitas Andalas \\ ${ }^{2}$ Badan Tenaga Atom Nasional, Jakarta
}

\begin{abstract}
ABSTRAK
Telah dilakukan penelitian untuk mengetahui sifat-sifat fisis partikel dari beberapa jenis bedak bayi dan hubungannya dengan proses inhalasi. Parameter yang ditentukan antara lain kandungan unsur dalam bedak bayi yang dibandingkan dengan standar kualitas udara sekitar yang ditetapkan EPA, konsentrasi partikel bedak bayi dan proses inhalasi bedak bayi. Penelitian ini menggunakan cascade impactor, XRF portable XMET-5100 dan software biokmod. Hasil penelitian menunjukkan bahwa kandungan unsur yang terdapat pada 7 sampel jenis bedak bayi ini Fe, Sn, $\mathrm{Zn}, \mathrm{Ca}, \mathrm{W}, \mathrm{Zr}, \mathrm{Sb}, \mathrm{Ti}, \mathrm{Mn}, \mathrm{Ni}, \mathrm{Sr}, \mathrm{Cr}$ dan $\mathrm{Cu}$ dan beberapa bedak bayi mengandung unsur Pb, Co, $\mathrm{Cd}$, dan Ta yang memiliki resiko terhadap kesehatan. Semua jenis sampel bedak bayi melebihi standar yang telah ditetapkan EPA yaitu sebesar $150 \mu \mathrm{g} / \mathrm{m}^{3}$ untuk $\mathrm{PM}_{10}$ dan $35 \mu \mathrm{g} / \mathrm{m}^{3}$ untuk $\mathrm{PM}_{2,5}$. Dengan menggunakan program biokmod proses inhalasi bedak bayi diperoleh pengendapannya lebih banyak pada $\mathrm{ET}_{2}$ yaitu bagian pharynx dan larynx, dan akan lebih banyak mengendap pada bayi yang berumur 3 bulan.
\end{abstract}

Kata kunci : Bedak bayi, partikel, konsentrasi bedak bayi, inhalasi.

\section{PENDAHULUAN}

Bedak sudah menjadi bagian dari kehidupan kita sehari-hari. Bedak bayi berbentuk bubuk yang terdiri dari butiran-butiran halus dari berbagai jenis bahan campuran. Bedak bayi biasanya digunakan agar bayi terhindar dari ruam kulit dan biang keringat, karena bentuknya yang berupa bubuk sehingga mudah berhamburan saat tertiup angin, dan halusnya ukuran butiran bedak maka sangat dimungkinkan butiran bedak ini terhisap melalui hidung. Bila hal ini dibiarkan, tentunya dapat berakibat buruk pada sistem pernapasan (Hinds, 2003, Suharyono, dkk., 2004).

Partikel bedak bayi yang berwujud padat dan berdiameter kurang dari $10 \mu \mathrm{m}$ yang biasanya disebut dengan $\mathrm{PM}_{10}$ (particulate matter) dan kurang dari 2,5 $\mu \mathrm{m}\left(\mathrm{PM}_{2,5}\right)$ diyakini oleh para pakar lingkungan dan kesehatan masyarakat sebagai pemicu timbulnya infeksi saluran pernafasan, karena pertikel padat $\mathrm{PM}_{10}$ dan $\mathrm{PM}_{2,5}$ dapat mengendap pada saluran pernafasan daerah bronki dan alveoli (Ruzer dan Harley, 2005, Djojodibroto, 2009).

Mengingat pemakaian bedak bayi dapat membahayakan sistem pernapasan bayi, maka perlu dilakukan penelitian sifat-sifat partikel seperti ukuran butiran partikel bedak bayi, kandungan unsur-unsur kimiawi bedak bayi dan proses deposisi partikel bedak ke dalam sistem pernapasan. Selain itu perlu juga diketahui seberapa besar konsentrasi partikel bedak tersebut yang masuk ke dalam sistem pernapasan. Dan karena halusnya ukuran partikel bedak ini, maka partikel-partikelnya akan cukup lama melayang-layang di udara dalam ruangan sehingga masih dapat dicium bau bedaknya. Penelitian ini perlu dilakukan untuk mengetahui sifat-sifat atau kelakuan partikel bedak bayi ketika di udara dan hubungannya dengan sistem pernapasan. 


\section{METODE}

\section{Menentukan Kandungan Unsur dalam Bedak Bayi}

Kandungan dan konsentrasi unsur-unsur di dalam bedak bayi dilakukan dengan mengukur sampel bedak bayi yang telah dituangkan ke dalam cup sampel, yang sebelumnya telah ditimbang dengan timbangan analitik agar setiap sampel massanya sama dengan merek sampel yang lainnya. Setelah itu sampel diletakkan pada tempat sampel XRF (X-Ray Fluorescence) portable XMET-5100, kemudian XRF portable XMET-5100 dan power PDA (Personal Digital Assistants) dihidupkan dan distel. Hasil kandungan sampel akan tertera di layar PDA, diulangi untuk sampel yang berbeda, dan data dapat di-download.

\section{Menentukan Konsentrasi Partikel Bedak Bayi}

Delapan filter milar dan filter serat gelas whatman digunting sesuai ukuran, sebelum digunakan disimpan 24 jam dalam desikator, agar terhindar dari pengaruh penambahan berat dari kelembaban udara, kemudian ditimbang dengan menggunakan timbangan digital satu persatu. Delapan stage orifice dan plat wadah filter dari cascade impactor dicuci dengan deterjen, setelah itu direndam dengan air di dalam ultra sonic selama 30 menit, lalu dikeringkan.

Komposisi cascade impactor terdiri dari stage (tingkat) orifice $0,1,2,3,4,5,6,7$, dan F. Filter serat gelas whatman yang sudah ditimbang dimasukkan ke dalam plat wadah filter di tingkat $\mathrm{F}$ yaitu tingkat yang paling bawah, kemudian filter-filter mylar yang sudah ditimbang masing-masing diletakkan pada tingkat $7,6,5,4,3,2,1,0$ dengan diameter pori-pori masing-masing berukuran $<0,4 ; 0,4 ; 0,7 ; 1,1 ; 2,1 ; 3,3 ; 4,7 ; 5,8 \mu \mathrm{m} ;$ dan 9 $\mu \mathrm{m}$.

Chamber analisis partikel dibersihkan sebelum digunakan, lalu manekin dan cascade impactor dimasukkan ke dalam chamber analisis partikel secara berdekatan. Cascade impactor dihubungkan dengan flowmeter dan pompa isap (generator listrik), dimana flowmeter diatur sedemikian rupa, sehingga laju alir yang masuk ke cascade impactor sebesar 28,3 liter per menit. Setelah semua terhubung, kemudian sampel bedak bayi dimasukkan ke dalam chamber, dan lubang chamber bagian kiri ditutup. Sampel bedak bayi ditaburkan menggunakan spon bayi ke seluruh bagian tubuh manekin, didiamkan selama dua menit lalu generator listrik dihidupkan. Setiap sampel bedak bayi didiamkan selama satu jam di dalam cascade impactor.

Sesudah pengambilan sampel, keseluruhan filter serat gelas whatman dan filter mylar dimasukkan ke dalam wadah compact disc (CD) dan dikondisikan 24 jam di desikator. Pada satu sampel bedak bayi, setiap satu set plat impaksi dalam wadah CD diberi label yang meliputi : nomor sampel dan jenis sampel. Keseluruhan filter setelah dikondisikan ditimbang. Dari selisih massa filter sesudah dan sebelum pengukuran, dibuat persentase massa setiap tingkat terhadap massa total seluruh tingkat.

Data-data partikel bedak bayi pada diameter partikel yang lebih kecil dari 0,43 sampai 10 $\mu \mathrm{m}$ yang terkumpul dari cascade impactor untuk menghasilkan konsentrasi partikel dan dapat ditentukan kecepatan pengendapan partikel pada cascade impactor menggunakan persamaan (1).

$$
V_{T S}=\frac{\rho_{a} d_{a}^{2} g C_{c}}{18 \eta}
$$

dengan $g$ percepatan gravitasi, $d_{a}$ diameter aerodinamik, $\eta$ adalah viskositas, $\rho_{\mathrm{a}}$ massa jenis udara $\left(1,2 \mathrm{~kg} / \mathrm{m}^{3}\right.$ pada kondisi standar) dan $\mathrm{C}_{\mathrm{c}}$ adalah faktor koreksi Cunningham 
atau faktor koreksi slip. Faktor koreksi slip 1,15 untuk partikel berukuran kurang dari 3 $\mu \mathrm{m}$ dan 1 untuk partikel yang berukuran besar dari $3 \mu \mathrm{m}$.

\section{HASIL DAN DISKUSI}

Hasil yang diperoleh menggunakan XRF portable XMET-5100 pada Gambar 1 menunjukkan log konsentrasi kandungan unsur bedak bayi, dimana pada setiap sampel bedak bayi memiliki berbagai macam kandungan unsur seperti Besi (Fe), Timah $(\mathrm{Sn})$, Seng (Zn), Kalsium (Ca), Timbal (Pb), Tungsten (W), Kadmium (Cd), Zirkonium ( $\mathrm{Zr}$ ), Sulfida (Sb), Tantalum (Ta), Cobalt (Co), Titanium (Ti), Mangan (Mn), Nikel (Ni), Strontium ( $\mathrm{Sr})$, Cromium $(\mathrm{Cr})$ dan Tembaga $(\mathrm{Cu})$.

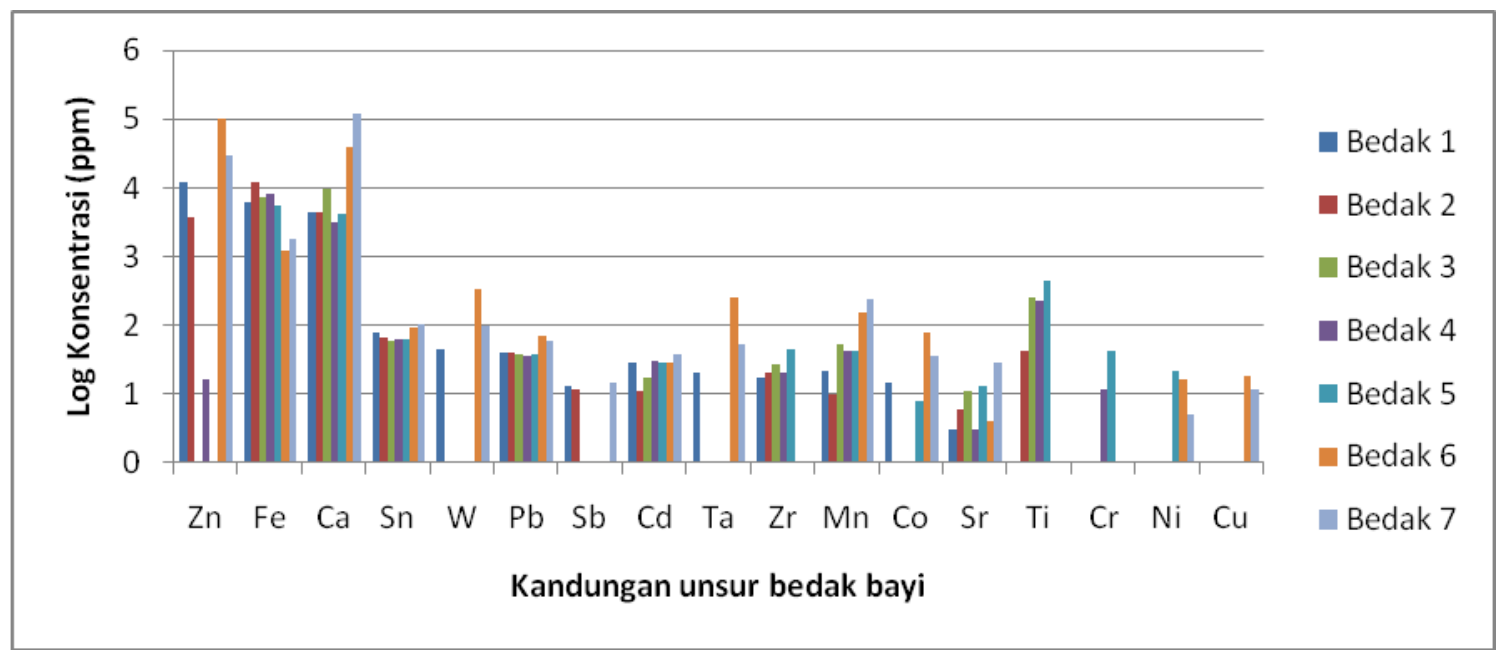

Gambar 1. Log kandungan unsur dalam bedak bayi

Ada beberapa kandungan unsur dari bedak bayi yang memiliki resiko terhadap kesehatan, diantaranya $\mathrm{Pb}, \mathrm{Co}, \mathrm{Cd}$, dan $\mathrm{Ta}$. Pada unsur $\mathrm{Pb}$ (timbal) dimiliki oleh setiap sampel bedak bayi, timbal sangat bebahaya bagi kesehatan terutama jika terhirup, karena dapat meluruh jika masuk ke dalam sistem pernapasan yang memiliki waktu paruh 22,2 tahun. Cobalt dengan simbol kimia Co terkandung di dalam bedak bayi, konsentrasi yang tertinggi terkandung di dalam bedak 6 sebesar 77 ppm.

Pada kandungan unsur kadmium dengan simbol kimia Cd sejenis logam yang biasanya digunakan dalam produksi baterai tetapi ada dimiliki oleh setiap sampel bedak bayi, berbahaya jika seringkali terpapar unsur ini dan dapat mengakibatkan pneumonistis, edma paru dan kematian. Selanjutnya terdapat kandungan unsur tantalum dengan simbol kimianya Ta yang biasanya digunakan untuk komponen elektronik dan pada sampel paling banyak terdapat pada bedak 6 sebesar $258 \mathrm{ppm}$. Maka dapat dilihat bahwa ada beberapa jenis unsur berbahaya yang terkandung dalam bedak bayi sehingga mempengaruhi resiko kesehatan bayi.

Selanjutnya didapatkan hasil konsentrasi bedak bayi menggunakan cascade impactor pada Gambar 2, bahwa ukuran partikel dan persentase partikel yang paling banyak ditunjukkan pada bedak 5, juga pada umumnya partikel bedak bayi yang diameternya lebih banyak adalah yang berukuran 5,8-9,0 $\mu$ m yang memiliki konsentrasi yang tinggi. 


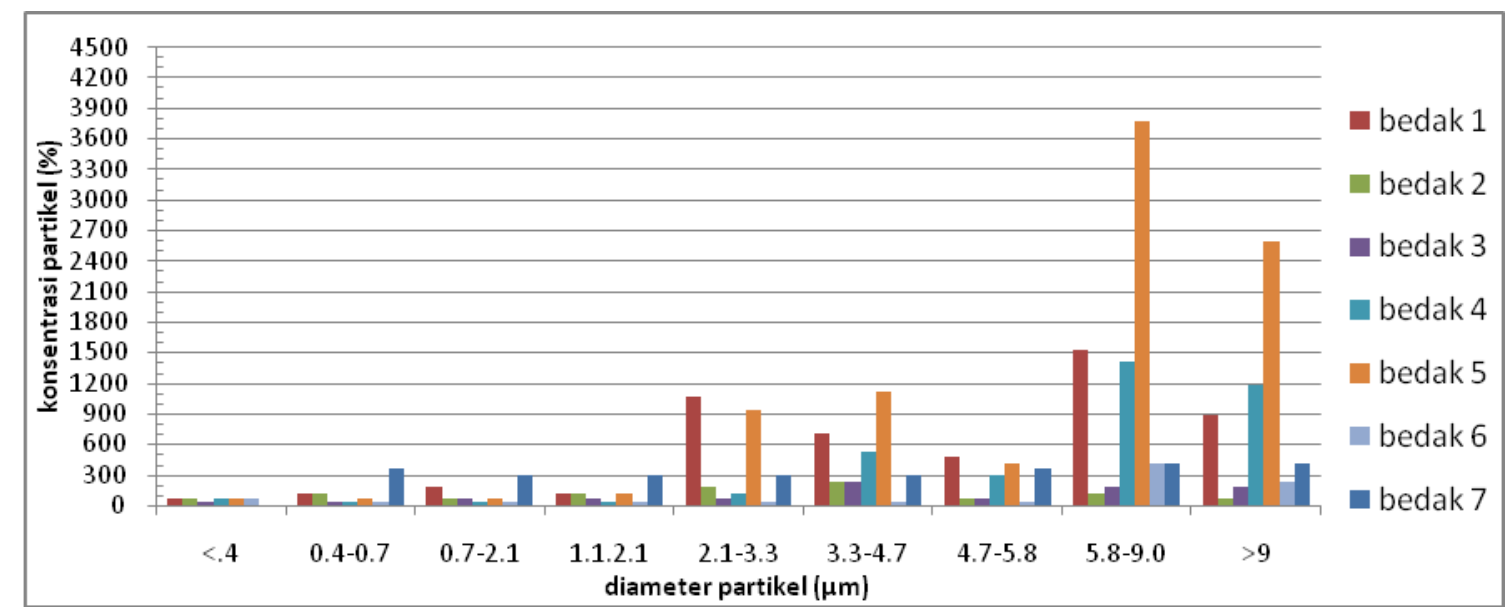

Gambar 2. Konsentrasi partikel bedak bayi

Tabel 1. Rata-rata konsentrasi partikel bedak bayi pada $\mathrm{PM}_{2,5}$ dan $\mathrm{PM}_{10}$

\begin{tabular}{|c|c|c|}
\hline \multirow{2}{*}{ jenis bedak } & \multicolumn{2}{|c|}{$\begin{array}{c}\text { konsentrasi partikel bedak } \\
\text { bayi }\left(\mu \mathrm{g} / \mathrm{m}^{3}\right)\end{array}$} \\
\cline { 2 - 3 } & PM2,5 & PM10 \\
\hline 1 & 259,13 & 2558,89 \\
\hline 2 & 194,34 & 365,301 \\
\hline 3 & 97,172 & 388,69 \\
\hline 4 & 80,97 & 1943,46 \\
\hline 5 & 161,95 & 4858,65 \\
\hline 6 & 80,97 & 404,88 \\
\hline 7 & 518,25 & 971,73 \\
\hline
\end{tabular}

Pada Tabel 1 dapat dilihat rata-rata dari konsentrasi partikel bedak bayi yang berdiameter kurang dari 2,5 $\mu \mathrm{m}\left(\mathrm{PM}_{2,5}\right)$ dan konsentrasi partikel bedak bayi yang berdiameter kurang dari $10 \mu \mathrm{m}\left(\mathrm{PM}_{10}\right)$. Nilai konsentrasi partikel $\mathrm{PM}_{2,5}$ yang paling rendah pada bedak 6 dan 4 sebesar $80,97 \mu \mathrm{g} / \mathrm{m}^{3}$ dan paling tinggi terdapat bedak bayi 7 sebesar $518,25 \mu \mathrm{g} / \mathrm{m}^{3}$. Untuk konsentrasi partikel $\mathrm{PM}_{10}$ yang paling kecil pada bedak 2 sebesar $365,301 \mu \mathrm{g} / \mathrm{m}^{3}$ dan yang paling tinggi pada bedak 5 sebesar $4858,65 \mu \mathrm{g} / \mathrm{m}^{3}$. Hal ini menunjukkan bahwa konsentrasi partikel bedak bayi didominasi oleh partikel yang berukuran besar $\left(\mathrm{PM}_{10}\right)$. Sehingga dapat dibuktikan bahwa konsentrasi pada $\mathrm{PM}_{2,5}$ dan $\mathrm{PM}_{10}$ melewati standar udara sekitar yang telah ditetapkan EPA yaitu sebesar $35 \mu \mathrm{g} / \mathrm{m}^{3}$ dan $150 \mu \mathrm{g} / \mathrm{m}^{3}$.

Dengan menggunakan Persamaan 1 didapatkan rata-rata dari kecepatan deposisi partikel di udara dalam chamber $\left(\mathrm{V}_{\mathrm{TS}}\right)$ yang ditunjukkan pada Tabel 2 bahwa bedak bayi yang paling cepat terdeposisi adalah bedak bayi 2 dengan diameter paling besar 14,25 $\mu \mathrm{m}$ dan kecepatan deposisinya $30,68 \times 10^{-7} \mathrm{~m} / \mathrm{s}$. Ini disebabkan karena ukuran partikel yang besar sehingga kecepatan partikel mengendap juga semakin besar. 
Tabel 2. Kecepatan deposisi partikel di udara dalam chamber $\left(\mathrm{V}_{\mathrm{TS}}\right)$

\begin{tabular}{|c|c|c|}
\hline Jenis Bedak & Dpg $(\boldsymbol{\mu m})$ & VTS $(\mathbf{x}$ 10-7 $\mathbf{~ m} / \mathbf{s})$ \\
\hline 1 & 3,59 & 4,67 \\
\hline \multirow{3}{*}{2} & 3,17 & 3,64 \\
\cline { 2 - 3 } & 4,1 & 6,1 \\
\cline { 2 - 3 } & 14,25 & 74 \\
\hline \multirow{2}{*}{3} & 2,66 & 2,95 \\
\cline { 2 - 3 } & 6,65 & 16,06 \\
\hline \multirow{3}{*}{4} & 2,55 & 2,71 \\
\cline { 2 - 3 } & 9,19 & 30,68 \\
\hline \multirow{3}{*}{5} & 3,24 & 3,81 \\
\cline { 2 - 3 } & 11,91 & 51 \\
\hline \multirow{2}{*}{6} & 4,1 & 6,11 \\
\cline { 2 - 3 } & 14,1 & 71 \\
\hline \multirow{2}{*}{7} & 4,11 & 6,1 \\
\hline
\end{tabular}

Berdasarkan ketetapan persentase deposisi partikel dari pemodelan biomod yang terdapat beberapa bagian pada sistem pernapasan yaitu pada lintasan extrathoraks (ET) terbagi ke dalam daerah $\mathrm{ET}_{1}$ (bagian hidung) dan daerah $\mathrm{ET}_{2}$ (bagian mulut, hidung belakang, pharynx dan the larynx). Sedangkan lintasan thoraks terbagi ke dalam daerah BB (Bronkhial), bronkhiolar (bb), dan alveolar-interstitial (AI) terdiri atas $\mathrm{AI}_{1}, \mathrm{AI}_{2}$, dan $\mathrm{AI}_{3}$. $\mathrm{LN}_{\mathrm{ET}}$ dan $\mathrm{LN}_{\mathrm{TH}}$ menyatakan lintasan ekstrathorak dan thorak, dimana faktor deposisi awal dari partikel yang terhirup. Maka didapatkan konsentrasi partikel yang mengendap (\%) pada sistem pernapasan bayi yaitu pada bayi yang berumur 3 bulan, 1 tahun dan 5 tahun. Pada semua jenis bedak bayi didapatkan jumlah partikel yang mengendap pada sistem pernapasan $\mathrm{ET}_{2}$ yaitu pada bagian pharynx dan larynx dan bayi yang banyak menghirup partikel tersebut adalah bayi yang berumur 3 bulan.

Hal ini dikarenakan faktor umur bayi yang masih kecil dan pola pernapasannya masih belum sempurna, perbedaan geometri saluran pernapasan dan peredaran darah. Usia juga mempengaruhi pernapasan nasal (pernapasan melalui hidung), sehingga partikel bedak bayi dengan mudahnya masuk ke sistem pernapasan bayi dan mempengaruhi jumlah partikel yang masuk ke dalam paru-paru. Berbeda dengan umur 1 tahun dan 5 tahun, dimana pola pernapasannya sudah mulai bagus yang dapat dilihat pada Tabel 3 . 
Tabel 3. Jumlah partikel bedak yang mengendap pada sistem pernapasan bayi yang berumur 3 bulan, 1 tahun dan 5 tahun

\begin{tabular}{|c|c|c|c|c|c|c|}
\hline \multirow{2}{*}{$\begin{array}{c}\text { Jenis } \\
\text { Bedak }\end{array}$} & \multirow{2}{*}{$\begin{array}{c}\text { Umur } \\
\text { Bayi }\end{array}$} & \multicolumn{5}{|c|}{ Konsentrasi Partikel yang Mengendap (\%) } \\
\hline & & ET1 & ET2 & BB & bb & $\Delta \mathbf{I}$ \\
\hline \multirow{3}{*}{ Bedak 1} & 3 bulan & 1073,66 & 1392,64 & 53,24 & 104,96 & 438,27 \\
\hline & 1 tahun & 1078,78 & 1397,76 & 53,24 & 87,55 & 493,56 \\
\hline & 5 tahun & 885,76 & 1142,78 & 52,73 & 94,72 & 504,32 \\
\hline \multirow{3}{*}{ Bedak 2} & 3 bulan & 209,7 & 272 & 10,4 & 20,5 & 85,6 \\
\hline & 1 tahun & 210,7 & 273 & 10,4 & 17,1 & 96,4 \\
\hline & 5 tahun & 173 & 223,2 & 10,3 & 18,5 & 98,5 \\
\hline \multirow{3}{*}{ Bedak 3} & 3 bulan & 185,16 & 240,17 & 9,18 & 18,1 & 75,58 \\
\hline & 1 tahun & 186,04 & 241,05 & 9,18 & 15,09 & 85,12 \\
\hline & 5 tahun & 152,75 & 197,08 & 9,09 & 16,33 & 86,97 \\
\hline \multirow{3}{*}{ Bedak 4} & 3 bulan & 771,69 & 1000,96 & 38,27 & 75,44 & 315,008 \\
\hline & 1 tahun & 775,37 & 1004,64 & 28,27 & 62,92 & 354,75 \\
\hline & 5 tahun & 636,64 & 821,37 & 37,9 & 68,08 & 362,48 \\
\hline \multirow{3}{*}{ Bedak 5} & 3 bulan & 1914,56 & 2483,36 & 94,95 & 187,16 & 781,52 \\
\hline & 1 tahun & 1923,69 & 2492,49 & 94,95 & 156,12 & 880,13 \\
\hline & 5 tahun & 1579,49 & 2037,81 & 94,03 & 168,9 & 899,3 \\
\hline \multirow{3}{*}{ Bedak 6} & 3 bulan & 185,16 & 240,17 & 9,18 & 18,1 & 75,58 \\
\hline & 1 tahun & 186,04 & 241,05 & 9,18 & 15,09 & 85,12 \\
\hline & 5 tahun & 152,75 & 197,08 & 9,09 & 16,33 & 86,97 \\
\hline \multirow{3}{*}{ Bedak 7} & 3 bulan & 568,28 & 737,12 & 28,18 & 55,55 & 231,97 \\
\hline & 1 tahun & 570,99 & 739,83 & 28,18 & 46,34 & 261,24 \\
\hline & 5 tahun & 468,83 & 608,87 & 27,91 & 50,13 & 266,93 \\
\hline
\end{tabular}

\section{KESIMPULAN}

Berdasarkan hasil penelitian dapat disimpulkan bahwa :

1. Kandungan unsur yang terdapat pada 7 sampel jenis bedak bayi ini adalah $\mathrm{Fe}, \mathrm{Sn}, \mathrm{Zn}$, $\mathrm{Ca}, \mathrm{Pb}, \mathrm{W}, \mathrm{Cd}, \mathrm{Zr}, \mathrm{Sb}, \mathrm{Ta}, \mathrm{Co}, \mathrm{Ti}, \mathrm{Mn}, \mathrm{Ni}, \mathrm{Sr}, \mathrm{Cr}$ dan $\mathrm{Cu}$. Ada beberapa kandungan unsur yang terdapat dalam bedak bayi tersebut memiliki resiko terhadap kesehatan jika terhirup sehingga dapat merusak sistem pernapasan seperti $\mathrm{Pb}, \mathrm{Co}, \mathrm{Cd}$, dan Ta.

2. Konsentrasi partikel bedak bayi didominasi oleh partikel lebih kecil dari $10 \mu \mathrm{m}$ $\left(\mathrm{PM}_{10}\right)$. Pada partikel yang lebih kecil dari $2,5 \mu \mathrm{m}\left(\mathrm{PM}_{2,5}\right)$ yang paling rendah pada bedak 4 dan 6 sebesar $80,97 \mu \mathrm{g} / \mathrm{m}^{3}$ dan paling tinggi terdapat bedak bayi 7 sebesar $518,25 \mu \mathrm{g} / \mathrm{m}^{3}$. Untuk konsentrasi partikel $\mathrm{PM}_{10}$ yang paling kecil pada bedak 2 sebesar $365,301 \mu \mathrm{g} / \mathrm{m}^{3}$ dan yang paling tinggi pada bedak 5 sebesar $48588,65 \mu \mathrm{g} / \mathrm{m}^{3}$. Terbukti bahwa konsentrasi pada $\mathrm{PM}_{2,5}$ dan $\mathrm{PM}_{10}$ melewati standar udara sekitar yang telah ditetapkan EPA yaitu sebesar $35 \mu \mathrm{g} / \mathrm{m}^{3}$ dan $150 \mu \mathrm{g} / \mathrm{m}^{3}$. Bedak bayi yang paling cepat terdeposisi adalah bedak bayi 2 dengan diameter paling besar 14,25 $\mu \mathrm{m}$ dan kecepatan deposisinya $30,68 \times 10^{-7} \mathrm{~m} / \mathrm{s}$.

3. Pada proses inhalasi bedak bayi terdapat jumlah pengendapannya lebih banyak pada $\mathrm{ET}_{2}$ yaitu bagian pharynx dan larynx, dan banyak mengendap pada bayi yang berumur 3 bulan. 


\section{DAFTAR PUSTAKA}

1. Hinds,W., 2003, Aerosol Tecjnology: Properties, Bevoir and Measurement of Airborne Particl. John Wiley and Sons, USA.

2. Suharyono, G., 2004, Analisis Partikel Udara di Sekitar Calon Tapak Penambangan Emas, Sumatera Utara, BATAN, Jakarta Selatan.

3. Ruzer \& Harley, 2004, Aerosol Handboo. CRC, New York.

4. Djojodibroto, D., 2009, Respirologi, EGC, Jakarta. 